\title{
Dental health and access to dental treatment: a comparison of drug users and non-drug users attending community pharmacies
}

\author{
J. Sheridan, ${ }^{1}$ M. Aggleton, ${ }^{2}$ and T. Carson, ${ }^{3}$
}

\begin{abstract}
Objective To investigate the self-reported oral health, access to dental treatment and recent use of dental services among a group of drug users attending community pharmacies and to make a comparison with a group of age and gender matched community non-drug users/patients not using services for drug users. Method Review instrument completed by pharmacist interviewing drug users and other pharmacy users.

Setting Community pharmacists

Sampling All known drug users attending participating pharmacies plus an equivalent number of age and gender matched non-drug using pharmacy customers. Final sample size drug users $N=125$; non-drug users $N=129$.

Key findings The data show that drug users self-report considerably more difficulty in accessing dental treatment, are less likely to have visited the dentist in the last 12 months and have a significantly higher level of self-assessed oral health problems, with less use of treatment services than non drug users. Conclusions Drug users need to be encouraged to access free dental treatment available to them on the NHS. Closer collaboration between the dental profession and others in contact with drug users, such as community pharmacists, may enhance uptake of dental services.
\end{abstract}

\begin{abstract}
Tlicit drug misuse can give rise to a number of oral health problems. ${ }^{1-9}$ The misuse of opiates is associated with a high rate of caries and periodontal disease and is greater than that seen in the general population. ${ }^{1}$ A high incidence of dental caries was identified in a group of 86 women attending a methadone maintenance clinic in Sydney, Australia. This problem was possibly attributed to their eating patterns and cravings for sweet food. ${ }^{10}$ Furthermore, opiates may mask the pain associated with dental disease. The misuse of stimulants (eg amphetamine, cocaine and crack cocaine) is associated with problems such as such as bruxism. In addition, cocaine use can cause ischaemic necrosis of the palate, ulceration and gingival problems.
\end{abstract}

\footnotetext{
$1^{*}$ Senior Research Pharmacist, National Addiction Centre, 4 Windsor Walk, London SE5 8AF; 2 formerly Community Pharmacy Project Manager, 3 formerly Community Pharmacy Facilitator, Kensington, Chelsea and Westminster Community Pharmacy Drug Reference Group, KCW Health Authority, 50 Eastbourne Terrace, London W2

${ }^{*}$ Correspondence to: Janie Sheridan

email: j.sheridan@iop.kcl.ac.uk

REFEREED PAPER

Received 20.09.00; Accepted 02.07.01

(C) British Dental Journal 2001; 191: 453-457
}

As illicit drug use is associated with a low expendable income, poor nutrition (especially the intake of foods high in calories and sugars), is common. Molendijk et al. ${ }^{7}$ found that over one third of a sample of Dutch drug users had a high level of sugar consumption. Malnutrition may be associated with angular chelitis, candidiasis and glossodynia. ${ }^{11}$ Lack of expendable income is also likely to place dental treatment far from the top of the list of life priorities and a chaotic lifestyle makes regular dental treatment difficult to provide. ${ }^{1}$ In particular, the management of opiate addiction can give rise to further oral health problems associated with the use of methadone as the main pharmacotherapy. Although there is little evidence for the impact of oral methadone on the health of drug users, all opiates reduce salivation, having an adverse effect on neutralising acids in the mouth. In addition, in the UK, methadone is usually prescribed as a mixture with a high sugar content (although the sugar-free version is sometimes prescribed). The mixture also has a low $\mathrm{pH}$ which may cause the enamel to be dissolved.

Despite the high prevalence of dental problems among drug users, many do not make adequate use of dental services ${ }^{1,6,7}$ and drug users may experience the stigmatisation they often incur when in contact with health professionals. Dentists, ${ }^{6}$ doctors ${ }^{12}$ and pharmacists ${ }^{13,14}$ have shown some reluctance to provide health care for drug misusers. In the UK, the added burden of trying to find a dentist willing to provide free or subsidised treatment as part of the National Health Service (NHS), may deter many drug users from accessing treatment except in emergencies.

For the dental profession there are a number of problems associated with providing treatment to this client group. A significant proportion of injecting drug users are hepatitis $\mathrm{B}$ and $\mathrm{C}$ positive; for hepatitis $\mathrm{C}$ there is currently no immunisation. While the occupational risk for dentists is considered to be relatively low, this may cause some dentists to try and avoid managing injecting drug users. ${ }^{15}$ In addition, drug users have been known to try to obtain opiate analgesics from dentists by deception. ${ }^{16,17}$ The problems associated with drug users failing to turn up for treatment, when an appointment has been made, have been noted. ${ }^{18}$

Despite these issues, the fact remains that drug users are likely to experience a greater number of dental problems than non-drug users, have problems accessing treatment especially if it incurs a charge, and may not perceive dental health issues to be of great importance.

All community pharmacies in the UK are in a position to dispense prescriptions for drugs such as methadone, for the management of drug dependence. In 1995, 50\% of pharmacies were dispensing such prescriptions for a mean of six patients. ${ }^{13}$ In addition, many offer a free needle and syringe exchange service - 
approximately 19\% of pharmacies in England and Wales. ${ }^{13}$ They therefore have frequent contact with large numbers of drug users, some of whom are in contact with drug treatment services, and others who may only be in contact with a health professional (the pharmacist) through accessing the needle exchange service. Community pharmacists are therefore in a position to gather information from a wide spectrum of drug users with regard to their dental health, recommend they register with a dentist if necessary and as primary health professionals, are in a position to work closely with their general dental practitioner colleagues.

In Kensington Chelsea and Westminster Health Authority (KCWHA) the Community Pharmacy Drug Reference Group (CPDRG) is focused on improving the health of illicit drug users through their contact with community pharmacy services. KCWHA is situated in inner London, covering an area with a high prevalence of drug misuse, including opiates and stimulants, with a large number of people being prescribed methadone for the management of drug misuse. A programme aimed at assessing and enhancing the oral health of drug users was initiated. The programme was in two parts:

1. A review of drug users dental health issues and comparison with other pharmacy users (non-drug users)

2. Referral of drug users, where appropriate, to local dentists willing to take part in the programme.

It is the first part of the programme that is reported here. The second phase will be reported elsewhere.

\section{Study aim}

The aim of this study was to investigate the dental health, access to dental treatment and recent use of dental services among a group of drug users attending community pharmacies for services such as needle and syringe exchange and the dispensing of their prescriptions for controlled drugs such as methadone, and to make a comparison with a group of age and gender matched non-drug users/patients attending community pharmacies.

The study was based on two hypotheses:

1. Drug users have poorer self-reported oral health than non drug users matched by age and gender

2. Drug users have experienced more problems accessing dental services than non drug users matched by age and gender.

\section{Method}

This study was implemented through the Kensington, Chelsea and Westminster Health Authority Community Pharmacy Drug Reference Group (CPDRG). It is the remit of this group to enhance the healthcare of drug users through community pharmacy services.

\section{Study design}

This study used a case-control study design. Pharmacists recruited drug users attending their pharmacies and recruited pharmacyattending controls (non-drug users) matched for age and gender (see below).

\section{Sample}

1. Drug users: Drug users using the prescription dispensing services for the management of drug dependence, for drugs such as methadone mixture $1 \mathrm{mg} / \mathrm{ml}$, methadone ampoules, methadone tablets and diamorphine ampoules. Injecting drug users using the free needle exchange services provided at participating community pharmacies. Drug users were asked to give their age, and their gender was noted.

2. Non-drug users: Pharmacy-using customers/patients [assumed not to be drug users as defined in (I)] either using the prescription dispensing service or purchasing health-related goods or obtain- ing advice at the pharmacy counter, matched by gender and approximate age to the drug using sample. This was accomplished by the pharmacist choosing a non-drug user who was the same gender as the drug user and appeared to be a similar age. They were asked to provide their age, and their gender was noted.

\section{Recruitment of pharmacies}

The CPDRG wrote to all community pharmacies in the Health Authority area asking whether they would be willing to take part in a programme to enhance drug users access to dental treatment. Pharmacists at 14 pharmacies were selected. However, data were only collected at 11 pharmacies.

\section{Development of dental review/intervention instrument (DRI)}

A dental review/intervention instrument (DRI) was developed by the CPDRG in conjunction with specialist expertise in addiction, in oral health, and with local participating pharmacists and dentists. The purpose of the DRI was twofold:

1. To review the level of need for dental services among drug using patients/clients presenting for services at community pharmacies and to compare these with non-drug users. This comparison was considered necessary to inform future service development beyond the intervention period.

2. To identify those drug users who needed to see a dentist (not reported here).

\section{The DRI covered the following issues:}

- Self reported oral health history over previous 12 months

- Access to dental care, including current registration with dentist, problems accessing local dental treatment

- Recent use of dental services

- Oral hygiene and use of regular check-ups

- (for drug users only) Treatment and harm reduction services used by clients eg methadone prescription and needle exchange.

\section{Procedure}

The review took place for a period of 2 months, or until DRI data had been obtained from 150 respondents in each group, which ever occurred first. An upper limit of 20 drug users and 20 non-drug users per pharmacy was established in order to limit a disproportionate number of questionnaires coming from single pharmacies. All drug users known to the pharmacist were approached and asked to complete the DRI. Pharmacists were also asked to recruit 150 non-drug users of the same gender and age group to the drug users for comparison. Pharmacists were paid $\mathfrak{E} 5$ per pair of drug user and non-drug user questionnaires, with a bonus of $£ 25$ for collecting 10 pairs, a further $£ 25$ for 15 pairs and a further $\mathfrak{E} 50$ for 20 pairs.

Drug users and non-drug users were asked to read the information on a laminated card which explained the purpose of the project. If, after reading the information, the drug user/non-drug user was willing to participate in the project they were asked to give consent by signing the project log sheet. Pharmacists administered the DRI by reading out the questions and entering the responses themselves.

\section{Results}

One hundred and twenty five drug users (DU sample) and 129 non-drug users (non-DU sample) completed DRIs at the 11 community pharmacies, giving a total sample size of 254 . There was a range of 11 to 38 study subjects per pharmacy [maximum of 20 drug user DRIs per pharmacy]. Four pharmacies completed $57.5 \%$ [146/254] of the data collection. (The extra four non-drug users may be explained by pharmacists recruiting a non-drug user prior to recruiting a drug user and then being unable to find a drug-using match). 
Table I Self reported difficulties accessing treatment or registering with a dentist

Category Self-reported problem $(n)$

Possible

discrimination:

Valid reasons for refusing treatment

Client not wishing to accept the dentist's recommended treatment
Told dentist I was taking methadone and refused me (I)

Because of drug use wanted blood tests to be carried out (I)

Problems registering because of $\mathrm{Hep} C(\mathrm{I})$

Because of methadone was refused access (I)

Because HIV+ (I)

Dentist in Chelsea was very snobbish (I)

Couldn't find dentist in area (I)

No concrete reason given - suspect reluctance

to treat drug user (I)

Excuses made (3)

Refused person who thought considering her age and drug usage she wasn't worth it (I)

[Dentist] looked at him and said we only do private, I knew they did NHS (I)

\section{Only takes private patients (7)}

Cosmetic work not on NHS (I)

Told were too busy ( 2 )

Refused treatment for being 5 minutes late for appointment (2)

Treatment ceased when payment was demanded (I)

I was drunk and hadn't washed for a

long time — I didn't approach a dentist again (I)

Refused anaesthetic (I)

One [dentist] wanted to remove all her teeth (I)

Told would have to be admitted to hospital to

have teeth removed $(\mathrm{I})$

Offered dentures but didn't want them (I)
Because of medication (2)

\section{Responder demographics}

Of the DU sample, $72.8 \%$ [91/125] were male and $27.2 \%$ female [34/125], with a mean age of 38.2 years [sd $=8.95$; range $17-61]$. For the non-DU sample 67.4\% [87/129] were male and $31.0 \%$ [40/129] were female with a mean range of 37.7 years $[\mathrm{sd}=9.4$, range $=16-69$ years $]$.

Ninety seven per cent of the DU sample were in receipt of a methadone prescription [120/124], of whom 58.0\% [69/119] were on oral methadone $[17.4 \%(12 / 69)$ of these were on sugar free formulations], 32.8\% [39/119] were on methadone ampoules and $9.2 \%$ [11/119] on a tablet prescription. Sixty per cent [75/125] used a pharmacy needle exchange service, $22.4 \%$ [28/125] used an agency needle exchange [some may have used both]. Only four individuals used needle exchange services alone, and were not being prescribed methadone. Only 37 individuals were prescribed methadone, but did not use needle exchange services

\section{Uptake of dental services}

Respondents were asked whether they had visited the dentist in the last 6 months. Thirty four per cent [43/125] of the DU sample had, compared with $66.6 \%$ [86/129] of the non-DU sample $\left[\chi^{2}=26.44\right.$; $\mathrm{df}=1 ; P<0.0001]$. Indeed, for $46 \%$ of the DU sample [58/125] a visit had not been made to the dentist for over a year (or not at all) compared with $15.5 \%$ [20/129] of non-DU sample $\left[\chi^{2}=28.48\right.$; $\mathrm{df}=1 ; P<0.0001]$. Only $16.0 \%$ of DU sample [20/125] had a check up every 6 months compared with $55.9 \%$ [72/129] non-DU sample $\left[\chi^{2}=43.56 ; \mathrm{df}=1 ; P<0.0001\right]$.

The median length of time since the DU sample had last visited the dentist was 29.8 months [sd $=47.8$; interquartiles $=5,12,36$; range $=0-276]$ and for the non-DU sample 11.3 months $[\mathrm{sd}=32.0$; interquartiles $=2,5,8.5$; range $=0-312$ ] [Mann Whitney $U=4877.5 ; P<0.0001$ ] ( 0 represents up to 1 month).
Difficulties registering with dentists and refused access to dental treatment

Respondents were asked whether they had ever had problems trying to register with a dentist. Twenty four per cent of the DU sample [28/117] had experienced difficulties and 67.5\% [79/117] had not, the remainder stating that they had never tried. This compares with only $0.07 \%$ [1/126] of the non-DU sample having experienced problems, 92.9\% [117/127] not experiencing problems and the remainder never having tried to register $\left[\chi^{2}=32.04\right.$; $\mathrm{df}=1$; $P<0.0001$ - those who have never tried have been excluded from this analysis].

There was a significant difference between the proportions of the DU sample and the non-DU sample registered with a dentist at the time of the study $[58.4 \%$ of the DU sample $(73 / 125)$ and $93.0 \%$ $(120 / 129)$ the non-DU sample] $\left[\chi^{2}=41.70 ; \mathrm{df}=1 ; P<0.0001\right]$

Respondents were also asked whether they had ever experienced being refused access to dental treatment. Only 1.6\% [2/129] of the non-DU sample had experienced this compared with $20.8 \%$ [21/125] of the DU sample $\left[\chi^{2}=23.98 ; \mathrm{df}=1 ; P<0.0001\right]$.

The DU sample identified a number of reasons why they were refused dental services, or had difficulty trying to register with a dentist (and therefore each person could give more than one reason). These have been categorised into four sections: possible discrimination, reasons relating to access to NHS treatment as opposed to private treatment, valid reasons for refusal, clients refusing dentists' recommendations (Table 1 ).

There was no significant difference in time since the last visit to the dentist between those who reported having difficulty registering with a dentist and those who have not (Mann-Whitney $U=$ 1053; $P=0.71$ ). Similarly there was no significant difference in time since last visit to dentist between those reporting having been refused access to treatment and those not reporting it (MannWhitney $U=1179 ; P=0.51$ ) (Table 2).

\section{Self-reported oral health problems}

Respondents were asked to provide information on the occurrence of oral health problems in the previous 12 months and whether they had consulted a dentist as a result of these problems. Data are summarised in Table 3. Twenty-one per cent [26/125] of the DU sample identified having no problems compared with $45.7 \%$ [59/129] of the non-DU sample. Seventy nine percent [99/125] of the DU sample had one or more problem compared with only $54.3 \%[70 / 129]$ of the non-DU sample $\left[\chi^{2}=17.73 ; \mathrm{df}=1\right.$; $P<0.0001]$. In all cases, the DU sample were more likely than the non-DU sample to have suffered from dental problems, the most common being toothache [58.4\%] and cavities [51.2\%]. However, fewer than $29 \%$ of the DU sample suffering dental problems had consulted a dentist, compared with the non-DU sample, where in all cases more than $36 \%$ had consulted a dentist.

\section{Oral health practises}

There was little difference between the two groups on how recently they self-reported having changed their toothbrush, with $49.6 \%$ of the DU sample [62/125] changing theirs within the last 2 months compared with $52.3 \%$ of the non-DU sample [67/128] $\left[\chi^{2}=0.19\right.$; $\mathrm{df}=1 ; P=0.66]$. However, the DU sample reported cleaning their teeth fewer times each day $[$ mean $=1.56$; $\mathrm{sd}=0.83]$ than the nonDU sample $[$ mean $=1.87$; sd $=0.59$ ] [Mann Whitney $U=5793.5$; $P<0.0001]$.

\section{Discussion}

This study presents data from a sample of drug users and non-drug users accessed through community pharmacies, with regard to their access to, and use of, dental services, and their self-reported oral health. The data show that for these two samples, drug users selfreport considerably more difficulty in accessing dental treatment, 
Table 2 Time since last visit to dentist: differences between those reporting: (a) difficulty registering and (b) being refused access

\begin{tabular}{|c|c|c|c|c|c|c|}
\hline & $\mathrm{N}$ & $\begin{array}{l}\text { Mean number of } \\
\text { months since } \\
\text { last visit to dentist }\end{array}$ & sd & $\begin{array}{l}\text { Inter- } \\
\text { quartiles }\end{array}$ & Range & Mann-Whitney U \\
\hline $\begin{array}{l}\text { Drug users } \\
\text { reporting having } \\
\text { difficulty registering } \\
\text { with a dentist } \\
(M C=10)\end{array}$ & $\begin{array}{l}\text { Yes }=28 \\
\text { No }=79\end{array}$ & $\begin{array}{l}27.1 \\
24.8\end{array}$ & $\begin{array}{l}49.4 \\
36.2\end{array}$ & $\begin{array}{l}3.5 ; 11.5 ; 23.3 \\
5 ; 9 ; 27\end{array}$ & $\begin{array}{l}\mathrm{I}-240 \\
\mathrm{I}-180\end{array}$ & $1053 ; P=0.71$ \\
\hline $\begin{array}{l}\text { Drug-users } \\
\text { reported having } \\
\text { been refused } \\
\text { access to dental } \\
\text { treatment }\end{array}$ & $\begin{array}{l}\text { Yes }=26 \\
\text { No }=99\end{array}$ & $\begin{array}{l}32.2 \\
29.1\end{array}$ & $\begin{array}{l}50.3 \\
47.3\end{array}$ & $\begin{array}{l}5 ; 13 ; 48 \\
5 ; 10 ; 36\end{array}$ & $\begin{array}{l}\mathrm{I}-240 \\
\mathrm{I}-276\end{array}$ & $\mathrm{II} 79 ; P=0.5 \mathrm{I}$ \\
\hline
\end{tabular}

sd = standard deviation

$M C=$ missing cases

Table 3 Dental problems in previous 12 months and whether dentist had been consulted

\begin{tabular}{|c|c|c|c|c|}
\hline & \multicolumn{2}{|c|}{ Drug user $(N=125)$} & \multicolumn{2}{|c|}{ Non drug user $(N=129)$} \\
\hline & $\begin{array}{l}\text { Self reported } \\
\text { problem } \\
n(\%)\end{array}$ & $\begin{array}{c}\text { Attended dentist } \\
n(\%)^{*}\end{array}$ & $\begin{array}{l}\text { Self reported } \\
\text { problem } \\
n(\%)\end{array}$ & $\begin{array}{c}\text { Attended dentist } \\
\qquad n(\%)^{*}\end{array}$ \\
\hline Toothache & $73(58.4)$ & $21(28.8)$ & $(22.5)$ & $22(75.8)$ \\
\hline Cavities & $64(5 I .2)$ & $17(26.6)$ & $(17.8)$ & $15(65.2)$ \\
\hline Lost a filling & $35(28.0)$ & $10(28.6)$ & $(16.3)$ & $10(47.6)$ \\
\hline Grinding teeth & $28(22.4)$ & $4(14.3)$ & $(3.1)$ & $2(50.0)$ \\
\hline Bleeding gums & $44(35.2)$ & $8(18.2)$ & $(22.5)$ & $11(37.9)$ \\
\hline Lost a tooth & $40(32.0)$ & $9(22.5)$ & (8.5) & $4(36.4)$ \\
\hline
\end{tabular}

* Percentage of those self-reporting a problem

are less likely to have visited the dentist in the last 12 months and self-report a significantly higher level of oral health problems, with less use of treatment services. A study of Dutch drug users found similar trends, with drug users having significantly poorer dental health than a sample of the general population. ${ }^{7}$

Drug users were less likely to have seen the dentist in the last year than non-drug users, were less likely to have regular 6-monthly check-ups and cleaned their teeth significantly fewer times per day than non drug users. These findings echo those from Molendijk et al., who noted that fewer than $36 \%$ of drug users in their study had visited the dentist in the last year and $18 \%$ brushed their teeth less than once a day. ${ }^{7}$ Furthermore, almost one quarter of drug users reported having experienced problems registering with a dentist compared with non-drug users and were more likely to have been refused access to treatment than non drug users, so one might conclude from these findings that it is poor access to dental treatment that has been the main cause of the greater level of oral health problems for drug users. However, on reviewing reasons given, we can see that not all are discriminatory and many may be seen as valid refusals to provide treatment. The data also show that there was little difference between drug users who had been refused dental treatment or had difficulty registering with a dentist compared with drug users who had not experienced these problems, in the time since their last visit to the dentist. For all drug users, the mean time since their last visit to the dentist was in excess of 2 years, compared with just under 1 year from non-drug users.

Therefore, other factors may be implicated in the poor oral health and lack of uptake of treatment. Drug users who have not been refused treatment may however, have felt that they might be stigmatised as patients. Studies have shown that health professionals often have negative attitudes towards drug users, ${ }^{12,14}$ and some dentists are reluctant to treat drug users ${ }^{6}$ and a more detailed study of drug users' experiences of dental services is needed. Negative experiences of health professionals might well deter drug users from accessing treatment until it is an emergency. Furthermore, many drug users are unable to tolerate pain, ${ }^{8}$ and are fearful of attending a dentist, as pain may not be adequately managed. Indeed, Scheutz noted that drug users suffered higher levels of anxiety associated with attending the dentist than a group of matched controls, ${ }^{3}$ and others have noted that the majority of drug users in their studies were afraid of attending the dentist. ${ }^{6,7}$ However, drug users in methadone treatment have been shown to place a high value on the need for dental care. ${ }^{19}$

The poor self-esteem experienced by many drug users means that they may well not perceive their appearance to be of major importance compared with the problems of being dependent on a drug. Scheutz noted that many young drug users only became aware of the poor state of their teeth during periods of abstinence, which caused them to become self-conscious about their appearance. $^{2}$ Finally, it is possible that there are significant differences between the two groups in terms of socio-economic status which is strongly predictive of oral health status and uptake of dental services. ${ }^{20}$

Whatever the reasons behind the lack of utilisation of dental treatment, the fact remains that the oral health of drug users in this study warrants further attention. Collaboration between general dental practitioners and service providers with regular contact with drug users, such as social services ${ }^{4}$ has been recommended. We propose that a greater collaboration between community pharmacists and dentists is needed. Further research into the feasibility of pharmacists referring drug-using clients to dentists is currently being undertaken and there is a need to further develop professional partnerships through discussions at a local level. 


\section{Limitations of the study}

Because of the sampling strategy used in this study, it is not possible to ascertain the denominator for the sample population. No data are available on the total number of drug-using patients/clients or nondrug users attending any one pharmacy. Pharmacists were asked to collect data from up to 20 drug-using patients/clients and no data are available for those who refused to take part. It is possible that this sample is therefore not representative of all patients/clients in the KCW area.

Furthermore, because of pharmacists being asked to match each drug user with a non-drug user by gender and approximate age (ie by making a visual judgement initially on the non-drug user's age), this is not strictly speaking a 'matched group'. However, as the data show, this procedure has produced two groups with similar demographics. We have not been able to adequately account for the existence of five additional non-drug users. However, it is clear that the instructions for carrying out these procedures need to be more clearly defined and audited in future research of this type.

This study was supported with funding from the CPDRG. The authors would like to express their thanks to all the participating pharmacists and dentists, and to the drug users and other pharmacy customers who took the time to complete the DRI.

1 Scheutz F. Five-year evaluation of a dental care delivery system for drug addicts in Denmark. Community Dent Oral Epidemiol 1984; 12: 29-34

2 Scheutz F. Dental habits, knowledge, and attitudes of young drug addicts. Scand J Soc Med 1985; 13: 35-40.

3 Scheutz F. Anxiety and dental fear in a group of parenteral drug addicts. Scand J Dent Res 1986; 94: 241-247.

4 Angelillo I F, Grasso G M, Sagliocco G, Villari P, D’Errico M M. Dental health in a group of drug addicts in Italy. Community Dent Oral Epidemiol 1991; 19: 36-37.
5 Rees T D. Oral effects of drug abuse. Crit Rev Oral Biol Med 1992; 3: 163-184.

6 Dawkes M, Sparkes S, Smith M. Dentists' responses to drug misusers. Health Trends 1995; 27: 12-14.

7 Molendijk B, Ter Horst G, Kasbergen M, Truin G J, Mulder J. Dental health in Dutch drug addicts. Community Dent Oral Epidemiol 1996; 24: 117-119.

8 Sainsbury D. Drug addiction and dental care. NZ Dent J 1999; 95: 58-61.

9 Bullock K. Dental care of patients with substance abuse. Dent Clin North America 1999; 43: 513-526.

10 Zador D, Lyons Wall P M, Webster I. High sugar intake in a group of women on methadone maintenance in South Western Sydney, Australia. Addiction 1996; 91: 1053-1061.

11 Freidlander A H, Gorelick D A. Dental management of the cocaine addict. Oral Surg Oral Med Oral Pathol 1988; 65: 45-48.

12 Glanz A. Findings of a national survey of the role of general practitioners in the treatment of opiate misuse: views on treatment. Br Med J 1986; 293 543-545.

13 Sheridan J, Strang J, Barber N, Glanz A. Role of community pharmacies in relation to HIV prevention and drug misuse: findings from the 1995 national survey in England and Wales. Br Med J 1996; 313: 272-274.

14 Sheridan J. Strang J, Taylor C, Barber N. HIV prevention and drug treatment services for drug misusers: a national study of community pharmacists' attitudes and their involvement in service specific training. Addiction 1997; 92: 1737-1748.

15 Cleveland J L, Gooch B F, Shearer B G, Lyerla R L. Risk and prevention of hepatitis $\mathrm{C}$ virus infection. Implications for dentistry. J Am Dent Assoc 1999; 130: 641-647.

16 Balevi B, Breen L, Kranowski J. The dentist and prescription drug abuse. J Can Dent Assoc 1996; 62: 56-60.

17 Crossley H L. Management of the active or recovering chemically dependent dental patient. MSDA Journal 1996; 39: 85-86.

18 Rosenstein D I, Van Stewart A. Dental care for patients receiving methadone. JAm Dent Assoc 1974; 89: 356-359.

19 Schmitz J M, Rhoades H, Grabowski J. A menu of potential reinforcers in a methadone maintenance program. J Subst Abuse Treat 1994; 11: 425-431.

20 Locker D. Deprivation and oral health: a review. Community Dent Oral Epidemiol 2000; 28: 161-169. 